\title{
OXYGEN TRANSPORT AND TRANSFER PROPERTIES OF ERBIA-STABILIZED BISMUTH OXIDE
}

\author{
I.C. VINKE, J.L. BAKIEWICZ, B.A. BOUKAMP, K.J. DE VRIES and A.J. BURGGRAAF \\ Laboratory for Inorganic Chemistry, Materials Science and Catalysis, Faculty of Chemical Technology, University of Twente. \\ P.O. Box 217, 7500 .AE Enschede, The Netherlands
}

\begin{abstract}
The electrode resistances of solid solutions of $75 \mathrm{~mol}^{2} \mathrm{Bi}_{2} \mathrm{O}_{3}-25 \mathrm{~mol} \% \mathrm{Er}_{2} \mathrm{O}_{3}$ with sputtered and with copressed gold gauze electrodes were compared. In contrast with literature no enhancement of the electrode process could be observed for the copressed electrodes. The measurements show an oxygen partial pressure dependence of power -0.5 for the electrode resistance. Additionally ${ }^{18} \mathrm{O}_{2}$ exchange results also point to a low oxygen coverage and dissociative adsorption of oxygen. The electrode surface contributes significantly to the electrode process.
\end{abstract}

\section{Introduction}

For electrochemical applications minimization of energy losses is of great importance. The choice of a highly conducting electrolyte is as important as the choice of a good electrode material and the choice of an optimal electrode configuration. It was shown previously that the solid solution $75 \mathrm{~mol}^{2} \mathrm{Bi}_{2} \mathrm{O}_{3}-$ $25 \mathrm{~mol} \% \mathrm{Er}_{2} \mathrm{O}_{3}$ (BE25) is an excellent electrolyte material [1]. In a more recent paper [2] it was shown that, for this material, the electrode material is of minor importance as only little difference in pumping rates and oxygen exchange currents were observed for sputtered and annealed gold or platinum electrodes.

In this paper we focus on the third of the optimization parameters i.e. the electrode configuration. Dumélié et al. [3] showed a remarkable improvement of the electrode performance of $\mathrm{Bi}_{0.571} \mathrm{~Pb}_{0.428} \mathrm{O}_{1.285}$ using copressed gold gauze electrodes instead of vacuum deposited gold electrodes. As the structure of sputtered and of vacuum-deposited electrodes are similar after annealing it is of interest to study the influence of using copressed gold gauze electrodes on BE25.

\section{Experimental procedures}

BE25 powder was prepared by coprecipitation as described by Kruidhof et al. [4]. For the experiments with sputtered electrodes, boules were pressed and sintered. From these boules disks were cut. Before applying sputtered electrodes on both faces of the disk these disks were polished with $0.5 \mu \mathrm{m} \mathrm{Al}_{2} \mathrm{O}_{3}$. The sputtered electrodes had an annular shape with an outer diameter of $10 \mathrm{~mm}$, and inner diameter of $5 \mathrm{~mm}$ and a thickness of approximately $300 \mathrm{~nm}$. For the experiments with the copressed gold gauze electrodes a piece of gold gauze of 1024 mazes per $\mathrm{cm}^{2}$ and a wire thickness of $0.06 \mathrm{~mm}$, was cut to the same shape as the sputtered electrodes. The gauze electrode was placed at the bottom of an uniaxial die which was filled with enough BE25 powder to produce a disk of approximately $1.5 \mathrm{~mm}$ thickness. After uniaxially and subsequently isostatically pressing the disk was sintered at $1125 \mathrm{~K}$ for eight hours to a relative density higher than $99 \%$. The disk was then cut to a diameter of $12 \mathrm{~mm}$ and carefully polished as to bring the gold gauze to the surface of the disk. On the opposite face of the disk a counter electrode was sputtered of the same dimensions as mentioned above. After sputtering the electrodes were annealed for one hour at $1123 \mathrm{~K}$.

The current-voltage measurements were performed potentiostatically in a three electrode cell [5] 
using a computer controlled Wenking Pos $85 \mathrm{~W}$ potentiostat. The voltage was changed stepwise. Measurements were performed after the system had reached a steady state. The current-voltage curves were analyzed in terms of a Butler-Volmer relation by a NLLS-fit procedure. This procedure incorporates the $R_{\text {u (nknown) }}$ (i.e. the contribution to the potential due to non Faradaic processes) as a fit parameter [6]. Frequency dispersion measurements were performed to independently establish the magnitude of $R_{\mathrm{u}}$. The impedance data were analyzed using the EQUIVALENT CIRCUIT software package [7]. Measurements were carried out in a temperature range of 650 to $1000 \mathrm{~K}$ and a $P_{\mathrm{O}_{2}}$ range of $1.10^{-3}$ to $1.0 \mathrm{~atm}$.

\section{Results and discussion}

Fig. 1 shows an example of an uncorrected $I-V$ curve for the sputtered gold electrode and for the gold gauze electrode, both at $994 \mathrm{~K}$ and $1 \mathrm{~atm} P_{\mathrm{O}_{2}}$. The results of the NLLS fit, represented by the continuous lines, show good agreement with the measured data. The difference in the values for $R_{\mathrm{u}}$ established from the $I-V$ curve fit and from the impedance analysis was typically around $10 \%$.

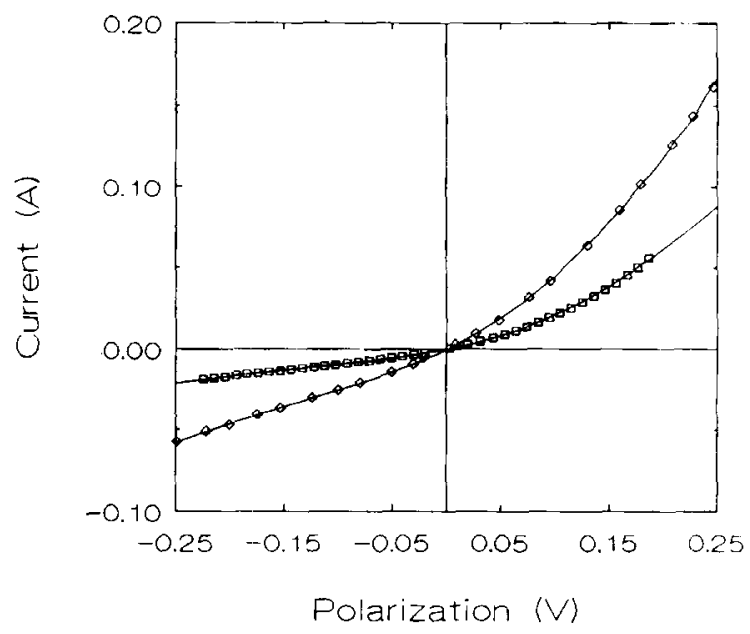

Fig. 1. Examples of the current-voltage curves as measured for sputtered gold electrodes $(\square)$ and copressed gold gauze electrodes $(\diamond)$ at $994 \mathrm{~K}$ in oxygen. The solid lines represent the NLLS-fit result.
The similarity between the shape of the $I-V$ curves in fig. 1 indicates that the electrode resistances, $R_{\mathrm{el}}$, are of the same order of magnitude. The difference between the curves are attributible to the $R_{\mathrm{u}}$. In this paper we will only discuss the influence of the electrode geometry on $R_{\mathrm{el}}$, a more elaborate analysis of the Butler-Volmer parameters, $I_{0}, \alpha_{\mathrm{a}}$ and $\alpha_{\mathrm{c}}$, will be presented in a future paper. The Arrhenius plot of fig. 2 shows the temperature dependence of $1 / R_{\mathrm{el}}$ at several $P_{\mathrm{O}_{2}}$ values. From this figure it is obvious that although difference exists between the $R_{\mathrm{cl}}$ values for sputtered and gauze electrodes, they are much smaller then expected, and in contrast with the findings of Dumélié et al. [3] for bismuth lead oxide. It is important to note that the length per unit area of the three phase boundary line is about a factor 100 larger for the sputtered electrode than for the gauze electrode. This indicates that the electrode geometry has only a minor influence on the rate of oxygen transfer on BE25. Earlier it was also observed that the electrode material (e.g. Pt and $\mathrm{Au}$ ) had only little effect on the electrode resistance [5].

On the other hand recent ${ }^{18} \mathrm{O}$ exchange experiments [8] on (bare) BE25 revealed very high surface oxygen exchange rates ( $K_{\mathrm{s}}$ exhibiting a power 0.5 dependence on the $P_{\mathrm{O}_{2}}$. Exchange current density values $\left(i_{0}\right)$ calculated from these $K_{\mathrm{s}}$ values were

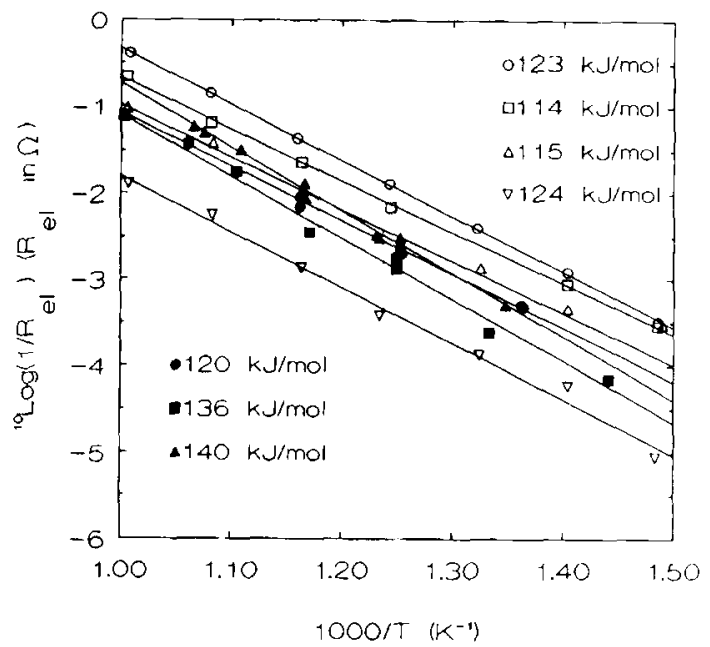

Fig. 2. Arrhenius plot of $R_{\mathrm{el}}$ for BE25 with copressed electrodes (open symbols) and sputtered electrodes (closed symbols) at several $P_{\mathrm{O}_{2}}$ values: $(O) 1.0 \mathrm{~atm},(\square) 0.21 \mathrm{~atm},(\triangle) 0.05 \mathrm{~atm}$, and $(\nabla) 0.001 \mathrm{~atm}$. 
found to be very close to values obtained from $I-V$ measurements [9]. Carefull analysis of the ${ }^{18} \mathrm{O}$ exchange data further suggested dissociative oxygen adsorption as the rate limiting step [8]. The same $\left(P_{\mathrm{O}_{2}}\right)^{0.5}$ dependence was observed for $1 / R_{\mathrm{el}}$ obtained from measurements on gauze electrodes, (see fig. 3). From literature [2] it is known that this dependency indicates a fractional oxygen coverage $(\theta)$ well below 0.5 . Combination of these electrochemically obtained results with those from isotope exchange experiments strongly suggests that the oxygen transfer reaction is not limited to a small "three phase boundary region" but rather involves a much larger part of the BE25 surface. From the above it becomes obvious that the oxygen transfer reaction for BE25 cannot be described in terms of existing reaction models. In a forthcoming paper this subject will be treated in relation with the other electrochemical parameters obtained from the analysis of the currentvoltage curves.

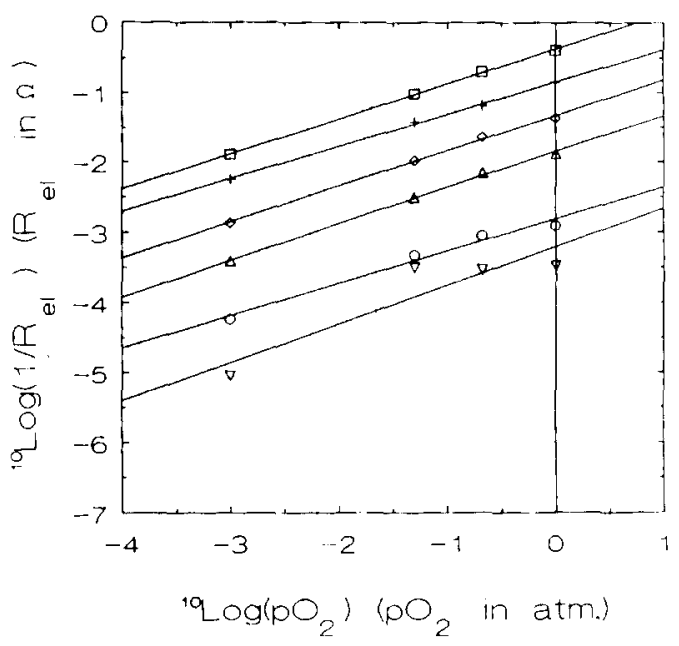

Fig. 3. Electrode resistances of BE25 with copressed gauze electrodes as function of $P_{\mathrm{O}_{2}}$ at several temperatures. $(993 \mathrm{~K}, 923 \mathrm{~K}$, $859 \mathrm{~K}, 804 \mathrm{~K}, 756 \mathrm{~K}$ and $673 \mathrm{~K}$ ).

\section{Conclusions}

(i) A substantial decrease in the electrode resistance by using copressed gold gauze electrodes, as observed for $\mathrm{Bi}_{0.571} \mathrm{~Pb}_{0.428} \mathrm{O}_{1.285}$ by Dumélié et al. [3], is not observed for BE25.

(ii) The electrode reaction is not restricted to a three phase line. It is most likely that a large part of the electrolyte surface is active, while the electrode only functions as a current collector.

(iii) The oxygen adsorption on BE25 is dissociative and fractional oxygen coverage of BE 25 is lower than 0.5 .

\section{Acknowledgement}

This investigation was supported by the Dutch Foundation for Chemical Research (SON) with the financial aid from the Dutch Organization for Scientific Research (NWO).

\section{References}

[1] M.J. Verkerk and A.J. Burggraaf, J. Electrochem. Soc. 128 (1981) 75 .

[2] M.J. Verkerk, M.W.J. Hamink and A.J. Burggraaf, J. Electrochem. Soc. 130 (1983) 70.

[3] M. Dumélié, G. Nowogrocki and J.C. Boivin, Solid State Ionics 28-30 (1988) 524 .

[4] H. Kruidhof, K. Seshan, B.C. Lippens Jr., P.J. Gellings and A.J. Burggraaf, Mat. Res. Bull. 22 (1987) 1635.

[5] I.C. Vinke, K. Seshan, B.A. Boukamp, K.J. de Vries and A.J. Burggraaf, Solid State Ionics 34 (1989) 235.

[6] B.A. Boukamp, I.C. Vinke, K. Seshan, K.J. de Vries and A.J. Burggraaf, Solid State Ionics 28-30 (1988) 1187.

[7] B.A. Boukamp, Solid State Ionics 20 ( 1986) 31.

[8] B.A. Boukamp, K.J. de Vries and A.J. Burggraaf, in: Nonstoichiometric compounds surfaces, grain boundaries and structural defects, eds. J. Nowotny and W. Weppner (Kluwer Dordrecht, The Netherlands, 1989) 299.

[9] B.A. Boukamp, I.C. Vinke, K.J. de Vries and A.J. Burggraaf, Solid State Ionics 32/33 (1989) 918. 